\title{
AS POLÍTICAS SOCIAS E A MUDANÇA DE RUMO DE NOSSA HISTÓRIA SOCIAL POLICIES AND CHANGE OF COURSE OF OUR HISTORY
}

\author{
DOI: 10.5533/1984-2503-20091201
}

\section{Patrus Ananias ${ }^{1}$}

\section{RESUMO}

Ao definir as políticas sociais como prioridade e eixo condutor de uma política de desenvolvimento sugere-se uma mudança substancial de paradigmas na história do país. Essa análise nos ajuda a perceber como se acumulou a dívida geradora de desigualdades sociais e nos dá a medida do impacto da mudança paradigmática em curso.

Palavras-chave: Políticas sociais, desenvolvimento, mudança de paradigmas, desigualdade social, exclusão.

\section{RESUMEN}

Al definir las políticas sociales como prioridad e hilo conductor de una política de desarrollo se sugiere un cambio sustancial de paradigmas en la historia del país. Ese análisis nos ayuda a percibir como se ha acumulado la deuda generadora de las desigualdades sociales y nos da la medida del impacto del cambio paradigmático en curso.

Palabras-clave: Políticas sociales, desarrollo, cambio de paradigmas, desigualdad social, exclusión.

\section{ABSTRACT}

When defining social policies as priority and conducting line of a development policy, a significant change of paradigm in the history of the country is

\footnotetext{
${ }^{1}$ Ministro do Desenvolvimento Social e Combate à Fome.
} 
suggested. This analysis helps us notice how social inequality was accumulated and gives us dimension of the developing paradigmatic change's impact.

Key words: Social policies, development, change of paradigms, social inequality, exclusion.

\section{RÉSUMÉ}

Avec la définition de politiques sociales en tant que priorité et axe central de la politique de développement, un substantiel changement des paradigmes de l'histoire nationale est à l'œuvre. Cette analyse nous aidera à percevoir de quelle manière se sont accumulées les inégalités sociales et nous donnera la mesure de l'impact du changement paradigmatique en cours.

Mots-clés: Politiques sociales, développement, changement de paradigmes, inégalités sociales, exclusion.

A descrição do nosso país evidencia os contrastes de nossa sofrida realidade, herdeira de uma dívida social acumulada por mais de 500 anos de exclusão. São contrastes que dão a medida do nosso desafio, diante da tarefa à qual estamos nos dedicando no Governo Nacional para reverter esse quadro e implantar aqui, em nossas terras, bases sólidas para um Estado de Bem Estar Social, com amplo potencial de influenciar não só na vida dos beneficiários diretos de nossas políticas, mas também no rumo do desenvolvimento de toda a nação, conferindo-lhe um caráter mais justo e, por isso, uma estrutura mais sustentável. Faz parte do grande arranjo interno que estamos fazendo para acertar o passo com nossa história e projetar uma nova nação com bases no desenvolvimento pleno de nosso potencial.

Ao definir as políticas sociais como prioridade e eixo condutor de uma política de desenvolvimento, o presidente Lula indica uma mudança substancial de paradigmas em nossa história, e que já apresenta os primeiros resultados. Para ter a dimensão do alcance das ações, é importante fazer uma breve retrospectiva histórica da evolução das políticas sociais no país. Essa análise nos ajuda a perceber como se acumulou a dívida geradora das nossas desigualdades, nos dá a medida do impacto da mudança paradigmática em 
curso e suas possibilidades de reflexos a médio e longo prazos, mas também a medida do muito que ainda temos a fazer para que possamos alcançar nosso objetivo.

\section{A acumulação da dívida}

Os números nos mostram os contrastes. Em 2007, no Brasil havia 184 milhões de habitantes vivendo num território de 8,5 milhões de quilômetros quadrados, dispondo de um produto interno bruto de aproximadamente $R \$ 2,89$ trilhões $^{2}$ em 2008. No entanto, essa riqueza é distribuída de forma profundamente assimétrica: em 2007 , os $10 \%$ mais ricos da população se apropriavam de $43,83 \%$ da renda nacional, enquanto os $50 \%$ mais pobres ficavam com apenas $14,74 \%$ da renda ${ }^{3}$. Um verdadeiro obstáculo para manutenção de ciclos sustentáveis de progresso. Em contrapartida, sustentando esse quadro, as políticas sociais foram consideradas como elemento secundário na agenda de políticas públicas ou implementadas como instrumentos clientelísticos, reproduzindo o ciclo de subdesenvolvimento e pobreza no país.

As origens dessa situação remontam ao começo do nosso processo de formação nacional. Principiamos nossa trajetória histórica com as Capitanias Hereditárias, uma relação comprometedora que ainda repercute nos nossos dias na (in)definição entre o público e o privado, porque os donatários tinham benefícios privados e poderes públicos.

As capitanias, ao contrário do que dizem certos historiadores, tiveram importante influência na história do Brasil, desdobrando-se posteriormente nas sesmarias e nos grandes latifúndios improdutivos que levaram um historiador conservador, mas arguto observador da realidade brasileira, Francisco Adolfo Varnhagen, a dizer, no século 19, que veio daí a mania do brasileiro por ter tanta terra. Terra que ele jamais conhecerá e muito menos explorará:

“(...) a mania de muita terra (que) acompanhou sempre pelo tempo adiante os sesmeiros, e acompanha ainda os nossos fazendeiros, que se regalam em ter matos e campos em tal extensão que levam dias a percorrer-se, bem que às vezes só a décima parte esteja

\footnotetext{
${ }^{2}$ Instituto de Pesquisa Econômica Aplicada (IPEA).

${ }^{3}$ Instituto de Pesquisa Econômica Aplicada (IPEA).
} 
aproveitada, mas se tivesse havido alguma resistência em dar o mais, não faltaria quem se apresentando a buscar o menos" ${ }^{\text {. }}$.

Posteriormente, ligado à questão das sesmarias, da grande propriedade improdutiva, totalmente desvinculada da sua função social, tivemos 0 coronelismo, com espaços muitas vezes de poder e de mando dentro ou até mesmo acima do próprio Estado. Abolimos tardiamente a escravidão, não tomamos medidas para integrar, na vida nacional, nos direitos e deveres da cidadania, os nossos antepassados escravos. Carregamos uma dívida também com nossos antepassados indígenas.

O fato é que a questão social no Brasil, até pouco antes da Revolução de 1930, era considerada como uma questão de polícia - e não de políticas públicas. O governo do Presidente Getúlio Vargas, com suas contradições, representou um marco histórico no Brasil, ao colocar a questão social na agenda nacional, ainda que sob uma perspectiva corporativista e autoritária, sobretudo a partir de 1937 e, mesmo assim, restrita a algumas categorias profissionais.

A Consolidação das Leis do Trabalho de 1943 foi voltada basicamente para os trabalhadores urbanos, do comércio, da indústria. Os trabalhadores rurais, os trabalhadores informais, os desempregados, as pessoas idosas e com deficiência, as pessoas pobres e outros setores mais fragilizados permaneceram excluídos das políticas públicas de proteção e promoção social.

A legislação trabalhista só chega ao campo em 1963, com a Lei 4214, que institui o Estatuto do Trabalhador Rural. Em 1971 - já no período da ditadura - é instituído por intermédio da Lei Complementar no 11, o Programa de Assistência aos Trabalhadores Rurais - Pró-Rural, executado pelo Fundo de Assistência do Trabalhador Rural - Funrural. Contudo, ainda amplos setores da população permaneceram excluídos das políticas sociais.

\section{A formação da consciência}

Um marco importante da história do Brasil foi o processo constituinte após o regime ditatorial, com ampla participação da sociedade, culminando

\footnotetext{
4 Varnhagen, Francisco A. (1975). História Geral do Brasil: antes da separação e independência de Portugal. V.1. São Paulo: Melhoramentos.
} 
com a promulgação, em 5 de outubro de 1988, da Constituição da República Federativa do Brasil. Conhecida como "Constituição Cidadã", ela coloca, pela primeira vez, as políticas sociais no campo das políticas públicas, na perspectiva ainda em construção no Brasil da seguridade social, abrangendo as políticas de assistência, previdência e saúde. A Constituição trata ainda especificamente da questão indígena, dos remanescentes de quilombos, das pessoas excluídas, sem renda, dos pobres, das pessoas com deficiência, das crianças e adolescentes.

Desdobrando a Constituição, tivemos, no início dos anos 90 do século passado, a promulgação de importantes leis civilizatórias. Em 1990, a Lei Orgânica da Saúde e o Estatuto da Criança e do Adolescente. Em 1993, a Lei Orgânica da Assistência Social - um passo importante para superarmos no Brasil o assistencialismo e o clientelismo.

Depois de um período marcado pelo neoliberalismo, em que as políticas sociais foram esquecidas ou secundarizadas em relação a uma visão míope da dimensão econômica, houve uma retomada, embora tímida, no final do governo do Presidente Fernando Henrique Cardoso, com o lançamento localizado, com cadastros fragilizados e dispersos, de alguns programas como - Bolsa Escola, o Bolsa Alimentação, o Auxílio Gás, o Programa de Erradicação do Trabalho Infantil (este mais antigo, lançado em 1996), o Agente Jovem, o Sentinela.

\section{Renovação paradigmática}

Somente no governo do Presidente Lula as políticas sociais voltaram a ter prioridade. A própria criação do Ministério do Desenvolvimento Social e Combate à Fome, em 2004, mostra essa prioridade, configurando um salto quantitativo e qualitativo. O orçamento da área social para 2009 - sem contar com os recursos previdenciários - é de $\mathrm{R} \$ 152$ bilhões. O Ministério do Desenvolvimento Social e Combate à Fome (MDS), que engloba políticas nas áreas de segurança alimentar, assistência social, renda de cidadania e geração de oportunidades de inclusão, responde por $\mathrm{R} \$ 32,7$ bilhões desse total. Pela primeira vez em nossa história, temos um Ministério com orçamento expressivo voltado exclusivamente ao atendimento das pessoas pobres no país. Nosso 
propósito é implementar as políticas sociais sob a perspectiva de políticas públicas garantidoras de direitos sociais, visando à redução de dois problemas que caminham juntos no Brasil, desde os tempos iniciais da colonização até nossos dias: a pobreza e a desigualdade social.

No passado, a experiência brasileira mostrou que o crescimento econômico sem redistribuição de renda foi insuficiente para criar um mercado interno capaz de dinamizar a economia e promover as bases para 0 desenvolvimento sustentável. Como mostra Celso Furtado ${ }^{5}$, a desigualdade e a pobreza são causas e não conseqüências do subdesenvolvimento. As atuais políticas públicas no governo brasileiro vão ao encontro dessas preocupações ao entender a agenda social como intrínseca e complementar à agenda econômica.

Vale lembrar que no século 20, o país foi palco de um forte desenvolvimento industrial sem, contudo, permitir que os benefícios desse processo fossem usufruídos por todos. Entre as décadas de 50 e 70 do século passado, embora o país tenha assistido a elevadas taxas de crescimento do $\mathrm{PIB}$, houve um aprofundamento na desigualdade da distribuição da renda, da riqueza e das oportunidades. O Estado Brasileiro demorou a engajar-se de forma inequívoca na superação da pobreza e das desigualdades. Por meio da "verdadeira conspiração de silêncio", como dizia Josué de Castro ${ }^{6}$, o tema da fome ficou, ao longo de séculos, ausente da agenda política e intelectual no país.

Em 1988, a promulgação da nossa Carta Magna representa a ruptura com um passado de discriminação institucional do Estado que prevalecia no sistema brasileiro de proteção social construído a partir dos anos 1930, assentado sobre o modelo designado por Wanderley Guilherme dos Santos de "Cidadania Regulada" ${ }^{7}$, relacionando promoção dos direitos sociais à inserção do mercado de trabalho.

\footnotetext{
${ }^{5}$ Sobre essa abordagem, consultar: O Mito do Desenvolvimento Econômico (1974), Dialética do Desenvolvimento e Teoria e Política do Desenvolvimento Econômico.

6 Josué de Castro (1908-1973) é uma das principais referências no Brasil no estudo do problema da fome. Formado em medicina, foi professor, seguiu carreira diplomática e sua principal obra, Geografia da Fome, segue como referência a estudiosos do tema.

${ }^{7}$ Santos elabora o conceito de cidadania regulada para explicar a política econômico-social no pós-30 nos seguintes termos: "Por cidadania regulada entendo o conceito de cidadania cujas raízes encontram-se, não em um código de valores políticos, mas em um sistema de estratificação ocupacional e que, ademais, tal sistema de estratificação ocupacional é definido por norma
} 
A Constituição de 1988 promoveu muitos avanços no marco legal das políticas de seguridade social. Entretanto, esses avanços eram era fortemente destoantes das práticas até então vigentes das políticas sociais, estruturadas em torno de favores pessoais, num modelo de assistência marcado pela exigência do apoio político, da desestruturação dos serviços locais e da inexistência de normas e procedimentos regulares, como mostrou Victor Nunes Leal $^{8}$.

O texto constitucional de 1988 promove o importante arcabouço legal para institucionalização de uma rede de proteção e promoção social ampla e consistente. Nossa carta incorpora uma concepção de um Estado que seja a busca de uma síntese superior de integração e transcendência entre as conquistas do estado liberal, os direitos e garantias individuais, a afirmação da dignidade da pessoa humana e dos grupos intermediários como a família, as comunidades, o compromisso com as liberdades públicas, democráticas. Ao mesmo tempo incorpora as grandes conquistas do estado do bem estar, no que se refere aos direitos dos trabalhadores, dos pobres, das minorias, dos mais fragilizados, apontando também para vigorosas políticas de inclusão, de justiça social, como nós estamos, hoje, implementando no Brasil. Com base na Constituição se desdobraram, posteriormente, sistemas normativos importantes como o SUS (Sistema Único de Saúde), o SUAS (Sistema Único de Assistência Social), o Sisan (Sistema Nacional de Segurança Alimentar e Nutricional), o Estatuto da Criança e do Adolescente, a Lei Orgânica da Assistência Social, a lei que instituiu o Programa Bolsa Família, o Estatuto do Idoso, todas que regulamentam e traduzem na prática os princípios, os valores e as normas constitucionais.

No entanto, essa rede de proteção e promoção social só começa a se desenhar de maneira mais vigorosa a partir de 2003, com a determinação do Presidente Lula em honrar o compromisso feito com os brasileiros de erradicar a fome e a desnutrição no país. O Fome Zero é a síntese desse compromisso, se constituindo em uma estratégia que articula políticas, programas e ações em

legal. Em outras palavras, são cidadãos todos aqueles membros da comunidade que se encontram localizados em qualquer uma das ocupações reconhecidas e definidas em lei" (Santos, Wanderley Guilherme dos (1987). Cidadania e justiça: a politica social na ordem brasileira. $2 \mathrm{a}$ ed. revista e atualizada. Rio de Janeiro: Campus, p. 68).

${ }^{8}$ Leal, Victor Nunes (1975). Coronelismo, enxada e voto: o município e o regime representativo no Brasil. São Paulo: Alfa-Ômega. 
vários setores do governo para garantir o acesso à alimentação por parte das pessoas mais pobres no país. São 15 programas, que englobam 44 ações orçamentárias, divididas em seis ministérios, com orçamento executado em 2008 de $\mathrm{R} \$ 14,36$ bilhões.

Como estratégia, o Fome Zero parte do seguinte princípio: a situação de pobreza não se resume à insuficiência de renda. Ter baixa renda é o resultado de diversos fatores inter-relacionados, tais como baixa escolaridade, poucas oportunidades de qualificação, difícil inserção no mercado de trabalho, acesso a postos mal remunerados e sem perspectivas de progresso. Como agravante, a pobreza traz outra vertente que é sua reprodução entre gerações: filhos de pais pobres não têm as mesmas oportunidades de desenvolvimento educacional e de inclusão social que filhos de famílias mais abastadas. Portanto, o desenvolvimento social requer ações conjuntas e integradas, com vistas a promover o desenvolvimento em todas as suas dimensões. Essa concepção de integração vai nortear o caráter das políticas sociais do governo, na perspectiva da construção e consolidação da rede de proteção e promoção social. O combate à fome se apresenta como um vigoroso princípio coesionador e norteador das políticas na área.

\section{O propósito em ação}

A criação do MDS, em janeiro de 2004, consistiu em um importante fator para a institucionalização e articulação de políticas sociais no Brasil, com a formação de uma rede integrada de proteção e promoção social, articulada em quatro eixos, interdependentes e complementares: (1) segurança alimentar e nutricional, (2) assistência social, (3) transferência de renda com condicionalidades e (4) geração de oportunidades para a inclusão.

Uma característica importante e comum aos avanços nesses quatro eixos é a sua estruturação por meio de políticas públicas de Estado garantidoras de direitos, reguladas por leis e implementadas de forma republicana, como uma responsabilidade solidária das três esferas de governo, em parceria com a sociedade civil.

O eixo da segurança alimentar e nutricional está regulado pela lei federal número 11.346, publicada em 15 de setembro de 2006, e que instituiu o 
Sistema Nacional de Segurança Alimentar e Nutricional (SISAN), com o objetivo de integrar as políticas da área e assegurar o direito humano à alimentação adequada.

Um componente central da política de segurança alimentar e nutricional é o fortalecimento da agricultura familiar, que se dá por meio de dois programas: o Programa Nacional de Fortalecimento da Agricultura Familiar (PRONAF) e o Programa de Aquisição de Alimentos (PAA). O PRONAF, implementado pelo Ministério do Desenvolvimento Agrário (MDA) em parceria com o MDS, funciona como um grande sistema de microcrédito e assistência técnica rural a pequenos produtores em todo o país. Na safra 2008/2009, o programa disporá de um orçamento de $\mathrm{R} \$ 13$ bilhões.

O PAA, sob responsabilidade do MDS, atua em complementação ao PRONAF na promoção da segurança alimentar e nutricional tanto pelo lado da produção quanto pelo do consumo. Por meio desse programa, o governo federal garante a compra dos alimentos produzidos por agricultores familiares, com isenção de licitação, por valores referenciados pelos preços praticados nos mercados regionais até o limite do equivalente a $R \$ 3,5$ mil por ano. Os alimentos adquiridos são distribuídos a famílias em situação de insegurança alimentar e nutricional, creches e abrigos para idosos. O PAA pode ser considerado um dos programas que melhor expressam o conceito do Fome Zero: promove a segurança alimentar e nutricional por meio da distribuição da produção de alimentos da agricultura familiar para programas de alimentação escolar e populações sob risco de insegurança alimentar e impulsiona a emancipação das famílias de agricultores. Em 2008, o programa permitiu a compra direta de alimentos de 104 mil agricultores, atendendo 2.424 municípios e distribuindo $\mathrm{R} \$ 331 \mathrm{mil}$ toneladas de alimentos. Em 2009, o orçamento previsto para o programa é de $\mathrm{R} \$ 436$ milhões.

Para a estruturação das redes locais de segurança alimentar e nutricional, contribuem ainda o estabelecimento de um conjunto de equipamentos locais para facilitar o acesso a alimentos de qualidade a preços acessíveis, tais como restaurantes populares, bancos de alimentos e cozinhas comunitárias.

Outro fator de grande impacto para a garantia da dignidade humana é o acesso à água, que tem sido promovido por meio de diversas ações no âmbito 
do Governo Federal. O MDS participa com o programa de cisternas no semiárido brasileiro, implementado em parceria com organizações da sociedade civil. Já foram construídas mais de 245 mil cisternas, sendo 195 mil delas com recursos do MDS, beneficiando 1,1 milhão de pessoas. Para 2009, contamos com $\mathrm{R} \$ 55,3$ milhões para esse programa.

O segundo eixo, o da assistência social, também é caracterizado pela institucionalização e normatização de políticas públicas, estando organizado em torno do Sistema Único da Assistência Social (SUAS). O SUAS, criado em 2005, institui um novo modelo de organização dos serviços socioassistenciais e da gestão da política de assistência social de forma unificada em todo o território nacional, articulando as ações do Governo Federal, dos estados, dos municípios e do Distrito Federal.

O SUAS está sendo estruturado de acordo com os níveis de complexidade do atendimento - básico e especial. $\mathrm{Na}$ área de proteção básica, uma das ações importantes do sistema é o Programa de Atenção Integral às Famílias (PAIF), que se materializa por meio das unidades físicas da assistência chamadas de Centros de Referência de Assistência Social (CRAS). O CRAS é uma unidade pública estatal, localizada em áreas de maior vulnerabilidade social e realiza atendimentos às famílias, com orientação social e psicológica, identificação de demandas e encaminhamentos para outros níveis de complexidade do sistema. O CRAS organiza e coordena a rede local de serviços socioassistenciais, sendo a "porta de entrada" dos usuários na rede do SUAS. Atualmente, 3.187 mil municípios recebem co-financiamento do PAIF em 3,9 mil centros.

$\mathrm{Na}$ área de proteção especial do SUAS, os Centros de Referência Especial da Assistência Social (CREAS) foram planejados para realizar atendimentos em situações de violação de direitos. Em seu âmbito, são desenvolvidos programas e ações como o Sentinela e o Programa de Erradicação do Trabalho Infantil (PETI). O Sentinela é um serviço especializado para atendimento e proteção imediata às crianças e aos adolescentes vítimas de abuso ou exploração sexual, bem como seus familiares. São cerca de 150 mil crianças e adolescentes atendidas mensalmente pelo programa no país. $O$ PETI, implementado de forma articulada ao Programa Bolsa Família, transfere renda às famílias, tendo como contrapartida as condicionalidades do Bolsa 
Família $^{9}$ e a participação em ações socioeducativas no contraturno escolar. Em 2008, foram atendidas 871 mil crianças, em 3.471 municípios.

Uma ação estratégica no âmbito do SUAS é o Benefício de Prestação Continuada (BPC), direcionado aos idosos e pessoas com deficiência e que vivam em situação de pobreza. É um programa que paga um salário mínimo mensal a idosos com mais de 65 anos e a pessoas portadoras de deficiência com renda familiar per capita inferior a $1 / 4$ do salário mínimo que estejam incapacitadas para o trabalho. Em 2008, o BPC atendeu 1,5 milhões de idosos e 1,8 milhões de pessoas portadoras de deficiência.

No terceiro eixo das ações do MDS está o Programa Bolsa Família, criado pela lei federal número 10.836 , de 9 de janeiro de $2004^{10}$. Ele trabalha de forma integrada à rede de proteção e promoção social, em sintonia com outros programas, garantindo uma renda básica às pessoas em situação de pobreza, condicionada ao cumprimento de uma agenda de ações que visam romper o círculo vicioso da pobreza por meio da promoção da saúde e educação. O Programa está presente em todos os municípios brasileiros, atendendo a cerca de 11 milhões de famílias pobres. No início de 2009, o governo autorizou o aumento no teto da faixa para ingresso no programa, passando de $R \$ 120$ para $R \$ 137$, o que vai permitir inclusão de aproximadamente mais 1,3 milhão de famílias. Os recursos transferidos, em média $\mathrm{R} \$ 85$ por família, têm tido efeitos imediatos e significativos sobre as condições de vida da população pobre. Pesquisas apontam seu importante papel na redução da desnutrição infantil e na promoção da segurança alimentar e nutricional, além de possibilitar o acesso a bens básicos de consumo que melhoram sua qualidade de vida e sua auto-estima ${ }^{11}$ (SAGI/MDS, 2007).

\footnotetext{
${ }^{9}$ O Bolsa Família é um programa de transferência de renda com condicionalidades. Em troca do benefício, as famílias se comprometem a observar cuidados com a educação e saúde, como está explicado a seguir, na descrição do programa. A partir da integração com o PETI, a retirada das crianças da situação de trabalho precoce torna-se também uma condição para continuar recebendo o benefício. Como as condicionalidades dizem respeito a direitos elementares de cidadania, esse mecanismo torna-se, assim, uma forma de monitorar a oferta desses serviços por parte do Estado.

${ }_{10}$ O programa foi instituído em outubro de 2003, por meio de decreto presidencial. Posteriormente, o Congresso aprovou a lei citada.

${ }^{11}$ Pesquisa realizada em 2006 em conjunto pela Universidade Federal da Bahia e Universidade Federal Fluminense aponta que a principal utilização do benefício recebido pelas famílias é com alimentação. Das famílias beneficiadas entrevistadas, $86 \%$ relataram que houve melhora na alimentação da família. Os relatos também dão conta de que $93 \%$ das crianças das famílias atendidas fazem no mínimo três refeições diárias. Chamada Nutricional de 2006, realizada pelo
} 
Além dos benefícios financeiros, as famílias são incentivadas - por meio do acompanhamento das condicionalidades - a manter seus filhos na escola e a cumprir uma agenda de cuidados básicos de saúde (acompanhamento prénatal e do desenvolvimento infantil, vacinação) - o que contribui para ampliar suas capacidades e oportunidades de inclusão social. A garantia de um mínimo de renda, além de seus efeitos diretos e imediatos sobre a alimentação, o vestuário, o material escolar, fortalece o poder de negociação das pessoas em busca de trabalho. As pessoas podem se negar a trabalhar em condições aviltantes, insalubres, pois têm um mínimo de renda para a subsistência imediata.

O quarto eixo representa a nova fronteira das políticas de desenvolvimento social no país - a geração de oportunidades de inclusão. Atualmente, o eixo da geração de oportunidades para a inclusão está em plena estruturação, tendo como objetivo fortalecer o papel desempenhado pelo MDS na geração de oportunidades para a inclusão produtiva por meio de parcerias com outros órgãos e esferas governamentais e entidades da sociedade civil.

Essa nova área de atuação incidirá sobre a qualificação profissional, no acesso a oportunidades de emprego, no fomento ao associativismo e a projetos de economia solidária, dentre outras iniciativas. Um exemplo dessa atuação são as parcerias que estão sendo estabelecidas para que os beneficiários dos programas sociais do MDS, a partir das informações contidas no Cadastro Único - nosso registro das famílias em situação de pobreza no país - passem por um processo de qualificação orientado e sejam inseridos nas oportunidades de trabalho geradas pelo programa federal de investimentos em infra-estrutura, o Programa de Aceleração do Crescimento. O exemplo disso são os programas do Plano Setorial de Qualificação (Planseq) voltados para beneficiários do Bolsa Família, desenvolvidos em ação integrada de ministérios e parcerias com empresários.

MDS com 17 mil crianças na região do Semi-Árido brasileiro, aponta que, para o total de crianças menores de cinco anos, a participação no programa determinaria uma redução de quase $30 \%$ na freqüência da desnutrição (de $6,8 \%$ sem o programa para $4,8 \%$ com 0 programa). 


\section{Impactos na realidade}

O modelo de nossa rede de proteção e promoção social vem produzindo importantes resultados nos últimos anos, com destaque para a redução da pobreza e da desnutrição. O Brasil cumpriu, com antecedência de sete anos, o primeiro dos Oito Objetivos do Milênio estipulados pela Organização das Nações Unidas ${ }^{12}$. Entre 2003 e 2007, a redução no índice de pobreza foi de $33,14 \%$. A desigualdade também vem caindo, e o índice de Gini reduziu-se ao menor patamar nos últimos 30 anos. No entanto, apesar de tais progressos, os desafios se mantêm presentes. Embora em declínio, o índice de Gini ainda é elevado - 0,553 em $2007^{13}$ e o número de pessoas em domicílios pobres ainda corresponde a um contingente de 41,78 milhões de pessoas.

Além dos resultados de redução da pobreza, os dados indicam ainda que as políticas sociais vem possibilitando a superação da fome no país e a garantia do direito humano à alimentação adequada. Com o Programa Bolsa Família, 94\% das crianças passaram a comer pelo menos 3 vezes ao dia. Houve uma melhora na quantidade e qualidade dos alimentos consumidos. Cresceu o consumo de frutas, leite, massas e carne. A alimentação melhorou em 9 de cada 10 famílias; a variedade de alimentos consumidos aumentou em 7 de cada 10 famílias (SAGI/MDS, 2007).

Dados do Ministério da Saúde, de 2002 a 2007, mostram que as taxas de hospitalização por desnutrição e deficiências nutricionais caíram em todas as regiões do país. A redução média para o país foi de $35 \%$, chegando a $44 \%$ de queda na região nordeste, a mais vulnerável à situação de insegurança alimentar.

\section{Transformação em curso: desafios}

A dívida social brasileira é histórica e o caminho é longo. Mas é fato que as políticas sociais têm conseguido imprimir outra face ao país, demonstrando

\footnotetext{
${ }^{12}$ Segundo dados de estudo da Fundação Getúlio Vargas feito a partir de análise da Pesquisa Nacional por Amostra de Domicílio (PNAD) de 2006 do Instituto Brasileiro de Geografia e Estatística (IBGE), a extrema pobreza foi reduzida pela metade, como prevê o Objetivo número 1 da ONU: em 1992, 11,73\% da população brasileira vivia com menos de US\$ 1 ao dia. Em 2006, esse percentual era de 4,69\%.

13 Instituto de Pesquisa Econômica Aplicada (IPEA).
} 
a correção do rumo. A experiência brasileira mostra que, com comprometimento e prioridade para as políticas sociais, é possível superar a fome, a pobreza e a desigualdade.

O economista Amartya Sen, prêmio Nobel de Economia em 1998, mostrou, com o conceito de desenvolvimento humano, que a pobreza não diz respeito apenas a baixo nível de renda, mas à privação das capacidades básicas dos indivíduos, que Ihes limita as oportunidades na vida. Uma vez que desenvolvimento depende das capacidades que as pessoas adquirem ao longo da vida, baixos indicadores em áreas como educação, saúde, nutrição são decisivos na produção de pobreza e iniqüidade.

A integração dos mais pobres ao crescimento econômico é um dos pontos urgentes da agenda da modernização. Além da dimensão ética, moral, das políticas sociais, garantindo direito à vida, à educação, à alimentação de qualidade, à dignidade, têm efeito prático. Essas políticas incorporam novas pessoas no mercado interno e formam cidadãos também consumidores que dinamizam a economia. Estudiosos da área apontam que existem inúmeras evidências de que o investimento em necessidades básicas humanas melhora a produtividade e o crescimento econômico, trazendo uma taxa melhor de retorno dos investimentos. Um "crescimento pró-pobre" seria aquele que absorve trabalho e é acompanhado por políticas e programas que diminuem as desigualdades e facilitam a renda e a geração de emprego para os pobres, particularmente as mulheres e outros grupos tradicionalmente excluídos. Nossas políticas sociais, junto com outras medidas do governo federal como a preservação do poder de compra do Salário Mínimo, fortalecem o mercado interno e isso é uma de nossas proteções contra os efeitos de uma crise econômica.

Por esses, dentre outros, motivos, temos de avançar nas conquistas obtidas na área social até aqui, mantendo e ampliando investimentos e revigorando nossas políticas para que mantenham seu potencial de mudança. O contexto da crise econômica mundial, que se estabeleceu no terceiro trimestre de 2008 a partir do centro do sistema capitalista e se estende como ameaça a economias de países em desenvolvimento, reforça o nosso desafio de intensificar o ritmo de redução da pobreza e da desigualdade, inclusive como mecanismo de proteção da economia. 
Para isso, vamos precisar fortalecer a institucionalidade das políticas sociais que já se encontram em estágio avançado em relação ao nosso histórico de dívida social, mas que ainda carece de regulamentações que reforcem e estabeleçam, de maneira definitiva, os programas que compõem nossa rede de proteção e promoção social no status de políticas públicas duradouras e contínuas. Outra questão que se apresenta como fundamental no trabalho é o fortalecimento da articulação federativa. Os programas do nosso governo se destacam por seu caráter republicano, federativo, suprapartidário. E sabemos que o desafio da redução da pobreza e da desigualdade está posto não só ao governo federal, mas também aos governadores e, principalmente, aos prefeitos, que se encontram na ponta, em contato direto com os cidadãos. Para efetivar nossos programas de modo a aproveitar todo o potencial, precisamos de uma participação mais direta dos governos estaduais e também das prefeituras, a começar pelo empenho de aperfeiçoar as informações do Cadastro Único e incrementar mecanismos de monitoramento, controle e fiscalização do Bolsa Família. Para tanto, o MDS tem contribuído com repasse de recursos com base no Índice de Gestão Descentralizada (IGD), voltado para promover melhorias nessa área. Junto com governadores, os prefeitos também são importantes no monitoramento da frequência escolar e controle de acompanhamento de saúde e também para ampliação e consolidação de políticas emancipatórias, de capacitação, direcionando-as para as vocações regionais.

Por fim, mas não menos importante, temos a tarefa fundamental de aprofundar a intersetorialidade, as possibilidades de articulação e integração entre programas e ações governamentais. Nossos programas, como disse acima, se organizam em estrutura de rede, com possibilidades de ações conjuntas para trabalhar a questão social dentro da perspectiva de promoção do desenvolvimento integral e integrado.

Estamos superando a falsa dicotomia entre desenvolvimento econômico e social, provando que, na verdade, são questões interligadas, pois só conseguiremos um desenvolvimento sustentável com distribuição de renda e justiça social. Só com a inclusão de todos os brasileiros e todas as brasileiras no projeto de nação é que vamos materializar o que diz nosso hino nacional e 
fazer de nossa pátria, efetivamente, "mãe gentil" de todos os "filhos desse solo". 